\title{
PREFERÊNCIA PELA LIQUIDEZ E SISTEMA FINANCEIRO NO BRASIL: UM ESTUDO PARA O PERÍODO ENTRE 2000 E 2011
}

\author{
Wendy Beatriz Witt Haddad Carraro"
}

\begin{abstract}
RESUMO: Este artigo analisa o Sistema Financeiro Brasileiro com foco no setor bancário e seu grau de preferência pela liquidez, este entendido como o interesse dos agentes em conservar seus portfólios em ativos de maior liquidez vis-à-vis os de menor liquidez, como discutido por Keynes [1976(1936)]. Para esta proposta, efetua-se o cálculo dos índices de Preferência pela Liquidez dos Bancos (PLB) dos 20 maiores bancos brasileiros, no período 2000-2011, os quais representam 95\% do ativo total do setor bancário, avaliando o comportamento do referido índice de PLB segundo o tipo de controle acionário: público federal, público estadual, privado nacional e privado com controle estrangeiro; bem como em relação ao tamanho do banco. Os principais resultados sugeriram uma trajetória de redução geral da preferência pela liquidez em função do aumento das operações de crédito após 2007 Todavia, observou-se que, embora elevado, o índice de PLB é mais baixo para bancos privados e mais alto para os bancos públicos - federal e estadual. Com relação ao tamanho, os maiores bancos foram os que apresentaram os índices de PLB mais elevados. Esses resultados mostraram-se aparentemente contraditórios, tanto teoricamente, quanto relacionados às políticas econômicas adotadas desde meados dos anos 2000, sugerindo a importância de uma discussão mais profunda sobre as causas e, principalmente, as consequências de tal comportamento para o desenvolvimento econômico no país.
\end{abstract}

Palavras-chave: Sistema Financeiro; Preferência pela Liquidez; Setor Bancário; Economia Brasileira.

\section{INTRODUÇÃO}

A centralidade do desenvolvimento econômico coloca em evidência o papel do sistema financeiro e, consequentemente, a sua atuação no sentido de contribuir adequadamente com esse processo. Por um lado, os adeptos da visão da economia ortodoxa defendem que sua função é a de um intermediário neutro, cujo atributo é distribuir melhor a informação, de modo a diversificar as oportunidades de investimentos, minimizando os custos de agência entre tomadores e poupadores. Por outro lado, postula a visão pós-Keynesiana, que conferiu continuidade ao desenvolvimento dos argumentos de Keynes, que a moeda tem um papel importante e o adequado funcionamento da economia depende fundamentalmente das percepções e da atuação do sistema financeiro, pois bancos criam moeda-crédito para financiar a atividade econômica e, portanto, a demanda efetiva.

Dessa forma, o desenvolvimento econômico guarda uma forte relação com a ampliação do crédito. A maior disponibilidade de empréstimos permite que a demanda efetiva se expanda e, consequentemente, gere uma aceleração da trajetória de crescimento da renda e do emprego. O acesso ao crédito permite às famílias aumentar seu consumo de bens duráveis e investir, em especial, em residências e educação. Da mesma forma, a maior disponibilidade de financiamento de longo prazo, possibilita às empresas lançar empreendimentos de maior escala, particularmente em economias onde o mercado de crédito e de capitais é menos desenvolvido (SANT'ANNA; BORÇA JR; ARAÚJO, 2009).

Em se conferindo um papel ativo ao sistema financeiro, um fator que ganha relevância é a questão da preferência pela liquidez do sistema. A preferência pela liquidez foi discutida por Keynes a partir do reconhecimento de que a principal característica das economias monetárias de produção é a incerteza. Esta, ao afetar o estado de confiança dos agentes, reduz a sua base de conhecimento para o cálculo da renda esperada e, sem a garantia quanto às mudanças futuras e suas formas, os indivíduos preferem alocar seus recursos em ativos mais líquidos, e a moeda surge como o ativo líquido por excelência, por apresentar propriedades intrínsecas como rentabilidade mínima, liquidez máxima, e baixo custo de manutenção.

Quando os agentes agem dessa forma, ou seja, aumentam o seu grau de preferência pela liquidez, espera-se um efeito negativo sobre a demanda agregada, uma vez que os investimentos dos empresários em ativos produtivos

Doutora em Economia/PPGE /UFRGS/ Professora Adjunta/UFRGS 
são desviados para investimentos de maior liquidez, como por exemplo, investimentos financeiros. No caso do setor bancário, quando este agente também assume esta posição de busca pela "flexibilidade", há uma tendência de redução de sua disposição de emprestar recursos, afetando a oferta de crédito em determinada região, limitando assim sua capacidade de desenvolvimento.

O caso brasileiro chama atenção porque a relação crédito/PIB no país mais que dobrou nos últimos dez anos, passando de 23,6\% do PIB em 2004 para 50,7\% em 2013², todavia, esse percentual ainda é muito baixo quando comparado com o de outros países. Esta relação crédito/PIB em economias desenvolvidas é bem maior, por exemplo, nos Estados Unidos e Japão, representa cerca de 180\%, na Suíça e Grã-Bretanha, e 160\% e 90\% na Itália e França, respectivamente. Além disso, mesmo diante do crescimento do crédito, os bancos brasileiros apresentam alternativas muito interessantes, que aliam baixo risco e elevada rentabilidade, como por exemplo: os títulos públicos federais que são remunerados à taxa SELIC, que se constitui em um baixo incentivo para ampliar suas operações em outras áreas, como o consumo e, principalmente, a produção.

Cabe mencionar que, imediatamente após a crise financeira de 2008, no contexto de falta de liquidez generalizada e diante da posição mais apreensiva das instituições financeiras, a política econômica tentou influenciar as decisões dos bancos, particularmente dos bancos públicos, ampliando as linhas de crédito à disposição dos consumidores e das firmas, de modo que esses deveriam ser os primeiros a reduzir sua preferência pela liquidez e encabeçar a retomada de desenvolvimento. Como será observado ao longo desta pesquisa, o que ocorre normalmente no país é justamente o oposto, tais agentes possuem o mais alto grau de preferência pela liquidez do sistema, comparativamente aos demais bancos. Curiosamente, os maiores bancos deveriam ser os mais aptos a dinamizar o sistema oferecendo maior volume de crédito quando, de fato, isso não ocorre.

Diante do exposto, o objetivo deste artigo é analisar a evolução recente do Sistema Financeiro Brasileiro com foco no sistema bancário e em seu grau de preferência pela liquidez. Para cumprir o objetivo proposto efetua-se o cálculo dos Índices de Preferência pela Liquidez dos 20 maiores bancos brasileiros, que representam 95\% do ativo total dos bancos no país, avaliando o comportamento deste índice de acordo com o tipo de controle: público federal, público estadual, privado nacional e privado com controle estrangeiro, bem como em relação ao quesito tamanho do banco. O estudo é realizado a partir de uma análise das séries de tempo, elaborada com base nos dados disponibilizados no sítio do Banco Central do Brasil (BACEN), na seção de informações contábeis das instituições financeiras. A referência para análise foram os períodos trimestrais de 2000 a 2011.

Para cumprir com seu objetivo este trabalho encontra-se dividido em cinco seções, além de uma introdução e da conclusão. A segunda seção destaca a relação entre sistema financeiro e desenvolvimento a partir de duas abordagens principais, as visões tradicional e a pós-Keynesiana e faz uma discussão sobre o conceito de PLB. A terceira seção faz uma breve análise do sistema financeiro brasileiro atual, seguida da seção que apresenta a metodologia e o descritivo da base de dados utilizada. Finalizando esta pesquisa com a apresentação de seus resultados e respectivas análises.

\section{SISTEMA FINANCEIRO E DESENVOLVIMENTO ECONÔMICO}

Esta seção discute brevemente a relação entre sistema financeiro e desenvolvimento econômico, sob o enfoque de duas abordagens principais - a abordagem convencional (ortodoxa) e a abordagem pós-Keynesiana - pontuando as diferentes concepções dessas teorias quanto ao papel da moeda e o funcionamento do sistema financeiro. Na sequência, discute-se a questão da preferência pela liquidez enfatizada por Keynes, particularmente com o foco no comportamento do setor bancário, destacando suas características e implicações para o desenvolvimento econômico.

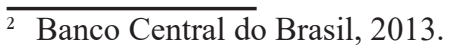




\subsection{O PAPEL DO SISTEMA FINANCEIRO NO PROCESSO DE DESENVOLVIMENTO}

O papel do sistema financeiro no processo de desenvolvimento econômico tem sido reconhecido, na fase recente, como um dos fatores relevantes no desempenho de um país.

Não obstante, as diferentes abordagens teóricas sobre sua atuação sejam divergentes, a relação entre sistema financeiro e desenvolvimento econômico é discutida a partir de duas abordagens principais: a visão ortodoxa, ou convencional e a visão pós-Keynesiana.

A abordagem ortodoxa aceita a visão de mundo em que há informação perfeita, mercados completos, sem friç̧ões. Dessa forma, o sistema financeiro é concebido como um intermediário financeiro neutro cuja existência se justifica, principalmente, pelo seu papel em diversificar as oportunidades de investimentos, bem como minimizar os custos de agência entre tomadores e poupadores de recursos.

A falta de informação perfeita pode ocorrer e, em se verificando tal fato, pode haver dificuldades em selecionar e encontrar as melhores oportunidades de investimento e financiamento, o que implica que o papel crucial dos intermediários financeiros é prover a melhor distribuição da informação para guiar poupadores e tomadores na melhor alocação de recursos (HERMANN; PAULA, 2011).

A teoria pós-Keynesiana, por sua vez, assume que em economias monetárias de produção predomina a complexidade do mundo real governado pela não neutralidade da moeda. O tempo é irreversível, pelo que as decisões de produção ocorrem antes do consumo e não podem ser revisadas, além disso, estão baseadas em expectativas de ganhos futuros, que podem ser otimistas ou pessimistas em relação ao futuro, que é incerto (DAVIDSON, 1994). Essas expectativas governam as decisões de portfólio dos agentes, que se fazem pelo valor presente, envolvendo estimativas que pode não se verificar pela incerteza, esta entendida como a completa ignorância a respeito de como será o futuro.

De acordo com o Ferrari Filho (2006), para Keynes, flutuações na demanda efetiva e no nível de emprego ocorrem porque, em um mundo no qual o futuro é incerto e desconhecido, os indivíduos preferem reter moeda e suas decisões sejam de gastos, de consumo ou investimentos são postergadas. E, portanto, booms e depressões são fenômenos peculiares para uma economia em que a moeda não é neutra.

A moeda se torna então, um refúgio contra a incerteza, pois é um ativo que possui propriedades peculiares - elasticidade da produção e elasticidade substituição igual a zero (ou negligenciável), adquirindo a característica de ativo de liquidez máxima e rentabilidade mínima, de forma que os agentes econômicos, que tem opiniões diferentes sobre o futuro (expectativas) podem optar por adiar projetos de investimento e preferir manter a riqueza na sua forma líquida (CARVALHO, 2007).

A partir dessa concepção de mundo, a visão pós-Keynesiana confere ao sistema financeiro um papel ativo no processo de desenvolvimento. Por um lado, está apto a garantir o crescimento econômico através do provimento de liquidez e na alocação das poupanças ex-post, na conversão dos títulos de dívidas de curto prazo das firmas em títulos de mais longa duração e, na medida em que as poupanças não são condição necessária para o investimento, o papel dos bancos é fundamental para a criação de poder de compra para as firmas que realizam investimentos.

\subsection{A PREFERÊNCIA PELA LIQUIDEZ}

A preferência pela liquidez é uma das mais interessantes contribuições da teoria Keynesiana e um importante recurso para justificar a inadequação da economia clássica em explicar o funcionamento do mundo real ${ }^{3}$.

Para a teoria clássica, a moeda era apenas um véu nas trocas e, tanto os preços quanto as taxas de juros eram perfeitamente flexíveis para ajustar a oferta e a demanda agregada, no nível de pleno emprego. Além disso, através da

\footnotetext{
Esta seção é baseada em Keynes (1983) cap. 12 e 17.
} 
teoria dos fundos de empréstimo, explicava que a taxa de juros era o preço que equilibrava as decisões de poupança $\mathrm{e}$ investimento da comunidade (oferta e demanda de recursos), sendo a primeira determinada pela propensão a poupar e o segundo pela eficiência marginal do capital.

A abordagem Keynesiana, por sua vez, enfatiza que preços e taxas de juros não eram perfeitamente flexíveis, pelo que o equilíbrio poderia ocorrer abaixo do nível de pleno emprego, ou seja, admitia a hipótese de desemprego involuntário. Entre as razões para que as taxas de juros não se ajustassem, estava o fato de que a moeda, suas funções e propriedades tinham importância em uma economia monetária de produção.

Dessa forma, a principal característica das economias monetárias de produção é a incerteza. A incerteza afeta o estado de confiança dos agentes, que inseridos em um mundo onde predomina a precariedade da base de conhecimento para cálculos da renda esperada e, sem certeza quanto às mudanças e à forma que estas possam ocorrer, o grau de confiança torna-se fraco, influenciando a eficiência marginal do capital e fazendo com que os indivíduos prefiram alocar seus recursos em ativos líquidos.

Aliás, Keynes também observou que o fato de existirem contratos nominais fixos e salários estáveis contribui substancialmente para que a moeda tenha um prêmio de liquidez bastante elevado, pois é conveniente para as pessoas alocarem a sua riqueza no mesmo ativo em que irão vencer os seus compromissos futuros. Assim, se existe um grau de incerteza em relação ao futuro, os agentes são incapazes de ter certeza sobre seus fluxos de renda futuros e, então, a melhor estratégia é alocar parte da sua riqueza no mesmo bem que ele utilizará para liquidar os contratos futuros.

Isso se justifica pelo fato de que a retribuição total que se espera receber da propriedade de um bem, ou melhor, a taxa de juros específica de um bem é igual ao rendimento menos o seu custo de manutenção mais o seu prêmio de liquidez $(q-c+1)$. Como pode ser observado, a taxa de juros específica, ou o rendimento que se espera receber com a retenção de um ativo, não está relacionada unicamente a um fluxo de renda monetária, mas também a uma forma de rendimento mais subjetivo, expresso pela conveniência de reter um ativo que possibilite uma proteção diante de um futuro incerto.

A relação entre q e 1 é inversamente proporcional, ou seja, quanto menos líquido for o ativo maior deve ser o seu rendimento em termos pecuniários. Uma vez que um agente só abriria mão de um ativo mais líquido e mais seguro para alocar a sua riqueza em um ativo menos líquido se este oferecesse a ele um rendimento que compensasse a diferença no grau de liquidez. Em outras palavras, para o empresário alocar a sua riqueza, por exemplo, em bens de capital, o rendimento esperado desse bem deve maior do que o risco que ele está automaticamente assumindo quando demanda por bens mais ilíquidos.

Pelo exposto, tem-se que a moeda, em uma economia monetária de produção também é um ativo, que tem como característica um rendimento nulo, um custo de manutenção insignificante e um prêmio de liquidez substancial. A diferença essencial entre a moeda e os demais bens é que, no caso daquela, o seu prêmio de liquidez excede muito o seu custo de manutenção, ao passo que, no caso dos demais bens, o custo de manutenção é maior do que o prêmio de liquidez.

Duas peculiaridades são inerentes à moeda. A primeira é o fato de esta possuir, tanto no curto como no longo prazo, uma elasticidade de produção igual à zero. Isso significa que os empresários não podem aplicar facilmente trabalho para produzir dinheiro em quantidades crescentes à medida que seu preço sobe em termos de unidades de salários. Em contraste, no caso dos demais bens, cuja produção demonstre elasticidade, o aumento de produção resultará em um aumento do estoque e, por conseguinte, em uma queda da taxa de juros.

A segunda peculiaridade da moeda é que esta possui uma elasticidade de substituição igual, ou quase igual, à zero. Assim, quando o seu valor de troca aumenta, não aparece nenhuma tendência para substituí-la por algum outro fator. Em termos mais específicos, um ativo líquido não pode ser substituído por um ativo reprodutível, pois, quando um agente demanda moeda, ele está alocando a sua riqueza de forma que ele fique protegido contra um cenário futuro incerto, e, a moeda surge como o ativo líquido por excelência. 


\subsection{SISTEMA BANCÁRIO E A PREFERÊNCIA PELA LIQUIDEZ}

Uma vez que é atribuído um papel importante para o sistema bancário no provimento de liquidez e na criação de poder de compra para novos investimentos, uma análise mais apurada do seu comportamento faz-se necessária.

Na visão pós-Keynesiana, a moeda tem um papel importante e o funcionamento da economia depende fundamentalmente das percepções e da atuação do sistema financeiro, pois bancos criam moeda-crédito para financiar a atividade econômica e, portanto, a demanda efetiva (JAIME JR.; ROMERO, 2007). Assim, moeda é criada endogenamente, na medida em que os bancos encorajam a alavancagem da atividade econômica.

Contudo, uma vez que a incerteza afeta a preferência pela liquidez e, com isso, a tomada de decisões dos agentes, as expectativas sobre o futuro, se pessimistas podem implicar, pelo lado da demanda, haverá uma tendência dos agentes econômicos em elevar a preferência pela liquidez, tornando-se menos dispostos a contrair dívidas, reduzindo assim, a demanda por recursos para investimentos produtivos.

Pelo lado da oferta de fundos, a maior preferência pela liquidez afeta poupadores e também o sistema bancário. Os primeiros tendem a conservar seus portfólios em ativos com maior grau de liquidez, interferindo no montante de fundos financeiros em determinado tempo e espaço. O setor bancário, por sua vez, também pode reduzir a sua disposição de emprestar recursos, afetando a oferta de crédito em determinada região, influenciando sua capacidade de desenvolvimento.

De acordo com Paula (1999), o comportamento dos bancos reflete não só a sua exposição ao ambiente de incerteza, mas também o seu intuito de obter lucro na forma monetária, estando sua escolha básica em função do interesse em conciliar rentabilidade e preservar a flexibilidade (liquidez) do seu ativo em um ambiente adverso.

Portanto, é com vistas às expectativas de rentabilidade e risco, que afetam o seu grau de preferência pela liquidez, que os bancos definem a sua estratégia de atuação. Isto significa que a disponibilidade de oferta de crédito poderá diminuir devido à maior preferência dos bancos pela liquidez, sem necessariamente, estar relacionada aos riscos inerentes aos empréstimos concedidos, fazendo com que o racionamento de crédito possa surgir quase que independentemente das rendas esperadas das suas atividades (PAULA, 1999).

Diversos trabalhos têm buscado estudar o grau, os determinantes e os efeitos da preferência pela liquidez do sistema bancário brasileiro. Cavalcante, Crocco e Jayme Júnior (2004) estudaram a questão do crédito na economia brasileira sob um enfoque regional, a partir da avaliação da preferência pela liquidez do público e dos bancos. Os autores verificaram que tanto a demanda como a oferta de crédito eram menores em regióes menos desenvolvidas, assim como era maior a preferência pela liquidez dos bancos nestas regióes, nas quais as estratégias de lucratividade não se baseavam na concessão do crédito. Jayme Júnior e Romero (2009) analisam a atuação dos bancos públicos e privados e sua capacidade de estimular a concessão de crédito e o desenvolvimento regional. O estudo demonstrou que a preferência pela liquidez dos bancos influencia na disponibilização de crédito, destacando que nos bancos públicos federais é mais elevada, tendo implicação para o dinamismo das regiões menos desenvolvida, o que demandaria por implementação de políticas públicas. Tada (2010) avalia a relação crédito bancário e desenvolvimento regional entre 2004 e 2009 no Brasil. O autor verifica através de um estudo de dados em painel que há uma relação heterogênea entre a variação do volume de crédito e produto, sendo que as regiões menos desenvolvidas apresentam menor volume de crédito e maiores volumes de índice de preferência pela liquidez bancária.

\section{O SISTEMA FINANCEIRO BRASILEIRO}

Esta seção destaca brevemente alguns aspectos da evolução recente do Sistema Financeiro Brasileiro, bem como apresenta algumas das suas características, tais como as referentes às operações de crédito, distribuição do crédito segundo os setores de atividades, segundo os tipos de recursos, entre outros aspectos pertinentes a presente análise. 


\subsection{EVOLUÇÃO RECENTE}

A estruturação de um sistema financeiro requerido ao desenvolvimento brasileiro teve, na reforma de 19641967, um marco relevante. Naquela ocasião foram tomadas diversas medidas no sentido de promover a criação de um mercado de capital e a reforma do sistema bancário ao estilo do modelo americano. Seu desenvolvimento ocorreu sob um contexto de elevada inflação ao longo das décadas de 1970 e até meados dos anos 1990, fato que lhe permitiu tirar proveito da situação, auferindo ganhos inflacionários (floating) (JAIME JR; ROMERO, 2007).

No ano de 1988, ainda no cenário de inflação elevada, outra reforma de menor magnitude foi realizada, desta vez, com o intuito de estabelecer um modelo universal de bancos a fim de estimular o desenvolvimento de um sistema de crédito privado de longo prazo e também um conjunto de medidas de liberalização financeira, cuja proposta era o estímulo do desenvolvimento das fontes de financiamento privadas internas e externas, do crédito e do mercado de capital, num mix de políticas que prosseguiram ao longo dos anos de 1990 (HERMANN; PAULA, 2011).

Após 1994, com o fim do processo inflacionário, um novo panorama das instituições financeiras com a forte redução do número de instituições bancárias no país, particularmente pela privatização de vários bancos públicos, como aumento da participação dos bancos privados nacionais e com controle estrangeiro.

De fato, nas últimas duas décadas, o setor financeiro a nível nacional e internacional, teve maior avanço com a multiplicação de inovações, grande desenvolvimento do tamanho do seu mercado, tendo em vista seu crescimento em Ativo Total bem como a questão do avanço tecnológico e de integração global, com abertura para bancos com controle estrangeiro. Entretanto durante este período, também ocorreram significativas alterações estruturais no setor bancário e atualmente a sua capacidade de converter em liquidez imediata a produção futura é muito maior do que em qualquer período da história.

Destaca-se que não houve antes uma sequência tão grande de crises financeiras como as que ocorreram nesse período. Elas acontecem praticamente a cada três anos. Iniciando no ano de 1987, houve a quebra do mercado de ações nos EUA; no final de 1989, no Japão, a quebra da Bolsa de Tóquio e o colapso do seu setor imobiliário; em 1990 a quebra do sistema e poupanças empréstimos e crise de crédito nos EUA, com a liberalização da conta de capitais, as sucessivas crise do México em 1994, da Ásia, em 1997, da Rússia em 1998, do Brasil em 1999, da Turquia e Argentina em 2001, ainda nos EUA a quebra do Long Term Capital Management em 1998, o estouro da bolha tecnológica Nasdaq em 2000, o alarme nos mercados de crédito em função dos escândalos contábeis pós-Enron e a crise brasileira em 2002. E finalmente a crise financeira de 2008 , que se iniciou com problemas de solvência no mercado de hipotecas "subprime" e que contaminou os demais mercados generalizando-se numa crise de crédito.

Nesse contexto e, ante os transbordamentos desses episódios sobre a economia brasileira, os reflexos sobre o sistema financeiro e seu comportamento não são desprezíveis. No entanto, a partir de 2004, tem-se uma tendência de elevação do volume de operações de crédito no país, que no período 2004-2012 quase dobraram como proporção do PIB. A economia aquecida e o nível do produto em níveis relativamente maiores, quando comparados à década de 1990, levaram ao aumento da expansão do volume de crédito, em todos os ramos de atividade, com destaque para o crédito para consumo.

Destacam-se também, o aumento do volume das operações de recursos livres e dos direcionados, principalmente a partir da crise de 2008. Não obstante, o custo do crédito no país figura entre os mais caros do mundo, com taxas médias mensais elevadas, tanto à pessoa física, quanto à pessoa jurídica, entre outros aspectos que são mostrados a seguir.

\subsection{CARACTERÍSTICAS RECENTES DA DISTRIBUIÇÃO DO CRÉDITO NO BRASIL}

Os gráficos 1, 2, 3 e 4 apresentam a evolução do volume de operações de crédito no período de 2000-2012, levando em conta o tipo de recurso, se direcionado ou livre; o crédito segundo os ramos de atividades; os repasses 
direcionados a cargos do BNDES, bem como a taxa de juros pagas pelas pessoas físicas e jurídicas nas operações contratadas.

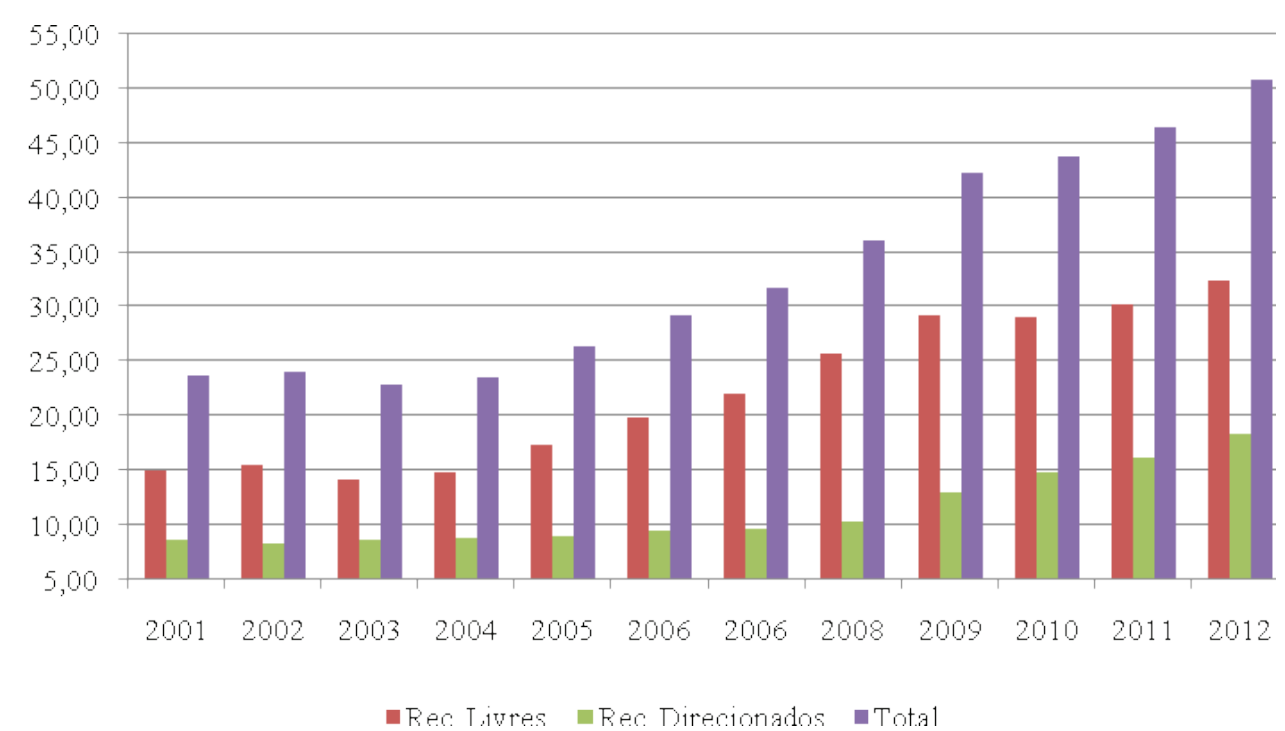

Gráfico 1. Operações de crédito, setores público e privado, total, recursos livres e direcionados,em \% do PIB: Brasil 2001-2012 Fonte: Elaborado a partir de BACEN (2014)

Uma primeira observação, a partir do gráfico 1, é o aumento do volume de crédito total como proporção do PIB no período analisado, o passou de 23,6\% para 50,7\%, principalmente, após 2007. Essa evolução foi maior no segmento dos recursos livres, que mais que dobrou no período analisado, passando de 14,8\%, em 2001, para 32,4\% em 2012. Os recursos direcionados também se expandiram significativamente passando de, passando de 8,8\% para $18,4 \%$, no mesmo período.

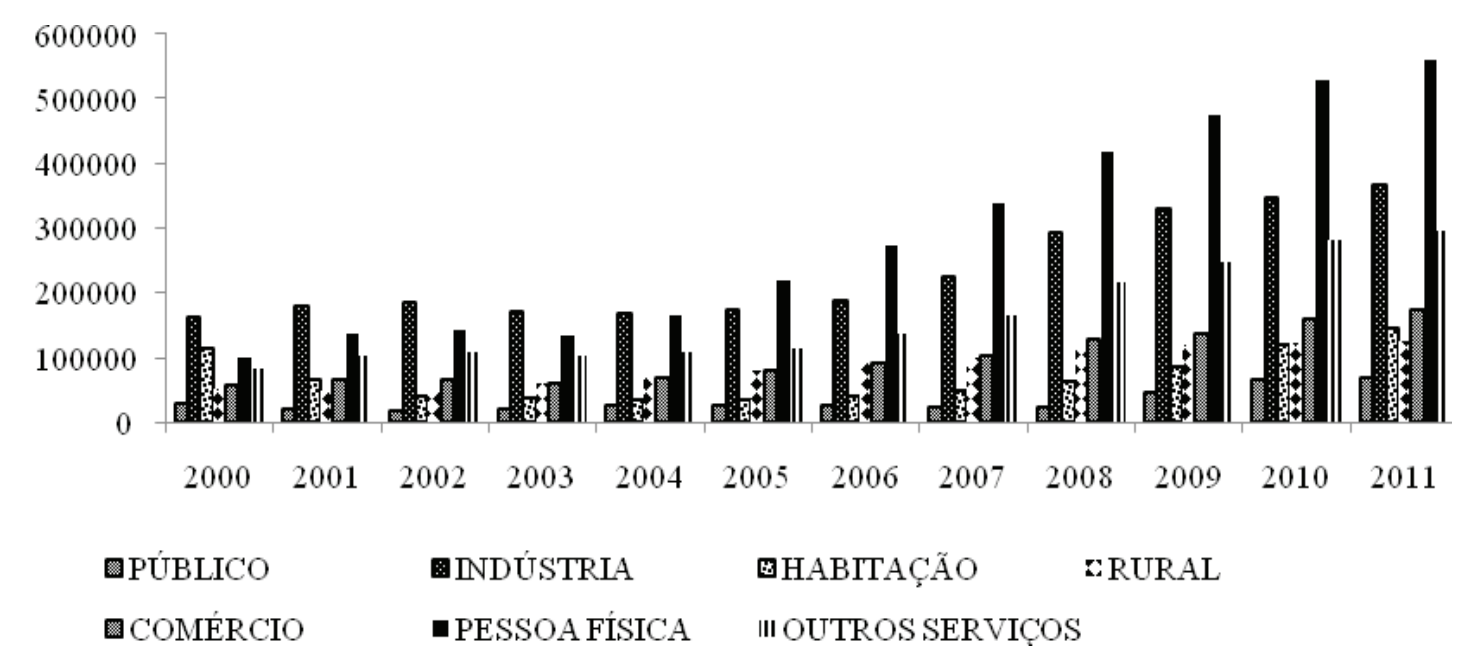

Gráfico 2. Operações de crédito, setores público e privado, segundo os ramos de atividades: Brasil 2000-2011 Fonte: Elaborado a partir de BACEN (2014)

O gráfico 2 permite analisar a evolução do crédito por ramos de atividade e mostra que os créditos que mais cresceram, no período 2000-2010, se direcionaram para os setores: comércio, $181 \%$; outros serviços, $242 \%$; chamando a atenção o crescimento do crédito à pessoa física, que registrou uma variação positiva de $427 \%$. Os setores em que o crédito menos cresceu foram: indústria, 111\%; setor público, 131\%; e rural, 135\%. A menor variação, no entanto, deu-se no setor da habitação que foi de $5 \%$. 


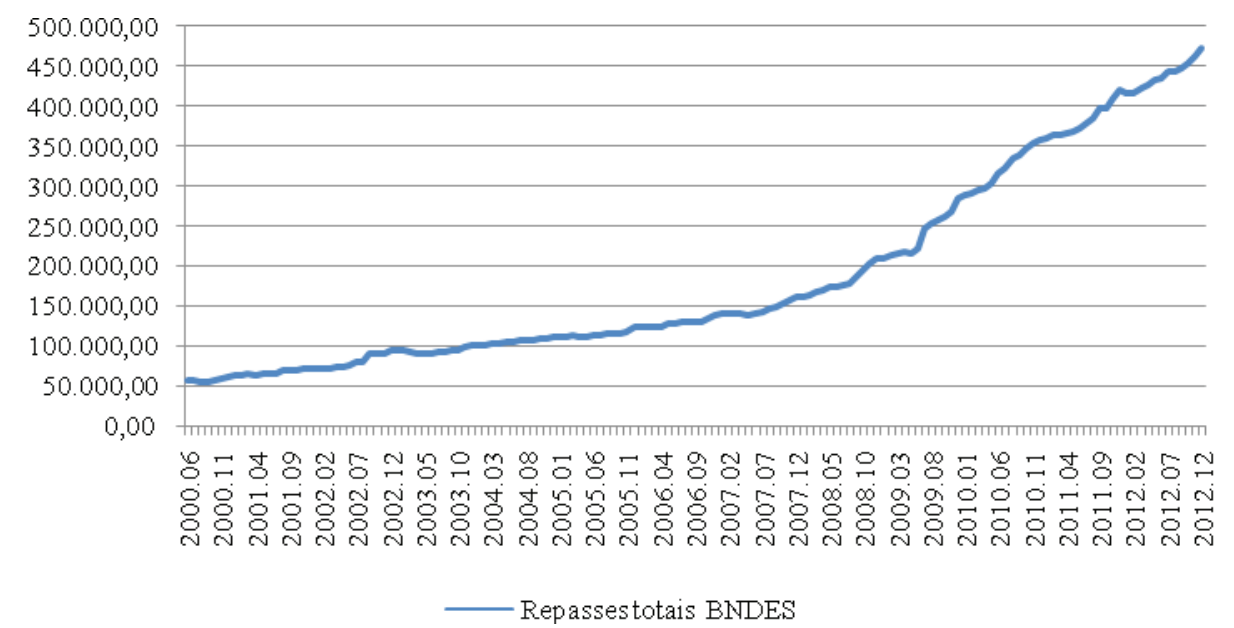

Gráfico 3. Operações de crédito (milhões de R\$), recursos direcionados, repasses do BNDES: Brasil, 2000-2012 Fonte: Elaborado a partir de BACEN (2014)

Um papel importante, destacado no gráfico 3, coube ao BNDES, cujo repasse de recursos se elevou expressivamente, de R \$56,1 para R\$ 471,7 milhões entre 2000 e 2012. Percebe-se a importância da atuação do banco, particularmente no período em que foi deflagrada a crise financeira internacional, quando suas operações de crédito se elevaram de forma acentuada, compensando a queda ocorrida no segmento de crédito privado.

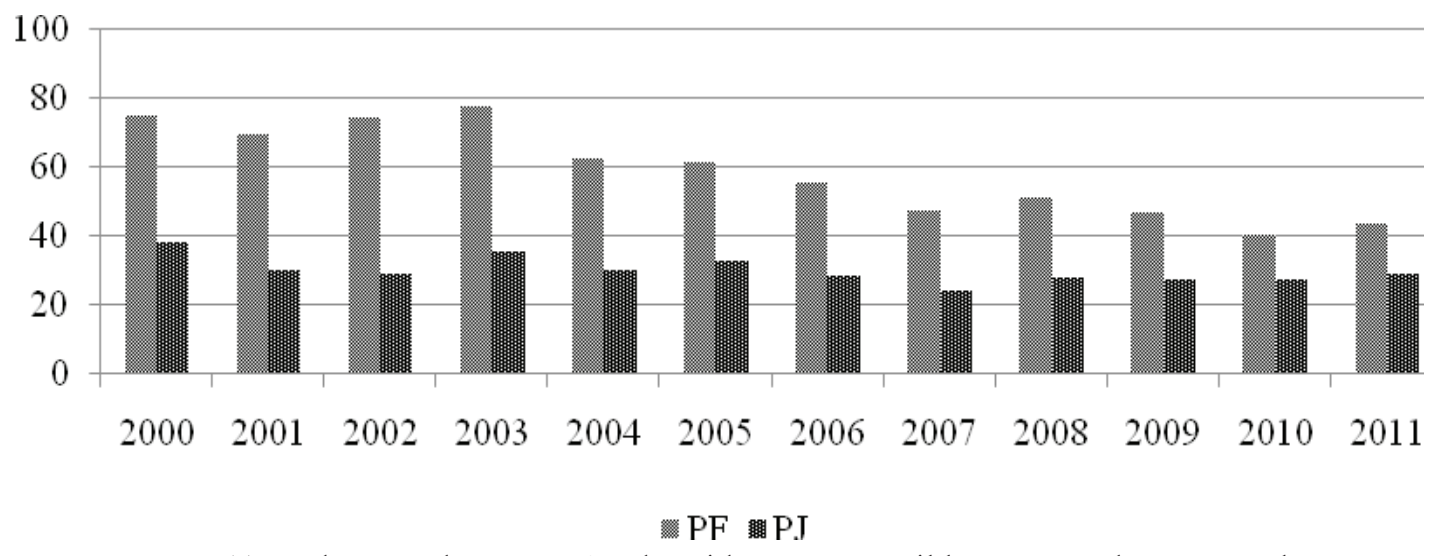

Gráfico 4. Taxas de Juros das operações de crédito, setores públicos e privado, recursos livres, Pessoa Física (PF) e Pessoa Jurídica (PJ) 2000-2011, \% a.a. Fonte: Elaborado a partir de BACEN (2014)

Finalmente, um último aspecto a ser considerado, destacado no gráfico 4 são as taxas de juros médias praticadas nas operações de crédito às pessoas físicas e jurídicas. Em relação à taxa de juros para as pessoas jurídicas nota-se que ela é significativamente menor em relação à pessoa jurídica, sendo oscilante ao longo do período 2000-2007 e se manteve em um patamar relativamente mais estável após 2008. A taxa cobrada da pessoa física, bem mais elevada, no entanto, inicia uma trajetória de queda substancial a partir do ano de 2004, ressalvada o período relativo à crise financeira. Esta taxa passou de 75,1\% em 2000 para 42,5\% em 2011. Uma observação relevante, mas não obstante a queda da taxa de juros, o spread cobrado nas operações de crédito à pessoa física, chama a atenção, registrando $27,7 \%$ em 2011, significando que o diferencial entre custo de captação e repasse onera de forma substancial os tomadores de recursos. 


\section{METODOLOGIA E BASE DE DADOS}

O estudo para análise do desempenho de Preferência por Liquidez pelos Bancos (PLB) foi elaborado com base nos dados disponibilizados no sitio do BACEN, na seção de informações contábeis das instituições financeiras. A referência para análise foram os períodos trimestrais de 2000 a 2011.

Inicialmente analisou-se a base completa disponibilizada pelo BACEN que conta atualmente com cerca 157 instituições financeiras na composição do Sistema Financeiro Nacional. Desta relação definiram-se como amostra, para análise dos dados, os principais bancos que representassem pelo menos $95 \%$ do somatório dos ativos totais dos maiores bancos ${ }^{4}$ no período de março/2011. Esta amostra corresponde a 23 bancos, dos quais foram excluídos aqueles bancos ${ }^{5}$ que não apresentaram saldo na conta de depósitos à vista, em função de sua natureza de operação, bem como bancos $^{6}$ que apresentaram o indicador analisado muito acima da média geral, ficando então a base de dados com a amostra de 20 bancos com maior representatividade em termos de ativo total no país.

A base de dados para análise foi constituída por contas específicas dos balanços patrimoniais das instituições financeiras (BACEN, 2011), especificamente as contas patrimoniais de ativo total, depósitos à vista e de operações de crédito e arrendamento mercantil total.

O índice de PLB, que foi calculado, teve como objetivo indicar o desempenho do setor financeiro e representa a relação entre o total de depósitos à vista e as operações de crédito. Os depósitos à vista correspondem à intenção do público de manter maior grau de liquidez. As operações de crédito representam a disposição dos bancos em concederem empréstimos tornando seus ativos menos líquidos. Quanto maior este índice, maior a preferência pela liquidez dos bancos, ou seja, ou os bancos estariam emprestando menos, ou o público estaria diminuindo suas aplicações em alternativas de menor grau de liquidez, como poupança e depósitos a prazo.

O critério de classificação dos bancos analisados é em relação ao tipo de controle ou estrutura de capital correspondendo aos bancos com controle Público Federal, Público Estadual, Privado Nacional e Privado com Controle Estrangeiro. Além disso, também são classificados em maiores e menores, segundo o tamanho do ativo.

\section{RESULTADOS E DISCUSSÃO}

Uma questão a ser considerada, antes de se proceder às análises propriamente ditas, é com relação é a apresentação prévia do perfil dos bancos. Com este intuito, elaborou-se a tabela 1 que apresenta o perfil dos bancos selecionados para a base de dados estudada, destacando o Total de Ativo e a média de PLB no mês de março de 2011, último ano da série analisada. A tabela 1 identifica nominalmente os bancos que representam a base de escopo deste estudo.

\footnotetext{
O BCB disponibiliza base de dados com as informações contábeis dos balanços patrimoniais dos maiores bancos, desta base identificou-se o \% de participacão de cada banco. Os bancos que representam $95 \%$ do total do Ativo desta base foram considerados como amostra deste estudo. Destacase que $80 \%$ do Ativo Total do sistema financeiro nacional estão distribuídos entre seis bancos, sendo destes, três bancos com controle Público Federal (BB, BNDES e CEF), dois com controle privado nacional (Itaú e Bradesco) e um com controle privado de controle estrangeiro (Santander).

5 Os bancos que foram desconsiderados da amostra por não apresentarem saldo na conta de Depósitos à vista foram o BNDES e Volkswagen, em função da sua natureza de operação.

$6 \mathrm{Na}$ análise detalhada do índice PLB foi desconsiderado o banco Deutsche que apresentou a média do indicador muito acima da média dos demais, considerado com outlier da amostra. Não foi escopo deste estudo identificar a justificativa desta divergência em relação aos demais.
} 
Tabela 1 - Perfil dos Bancos TOP 20 - volume de Ativo Total no período de 03/2011

\begin{tabular}{|c|c|c|c|c|}
\hline \multirow[b]{3}{*}{ Tipo de Controle } & \multirow[b]{3}{*}{ Instituições } & \multicolumn{3}{|c|}{ Data Balancete } \\
\hline & & \multicolumn{3}{|c|}{ SALDO BALANÇO 03/2011 } \\
\hline & & ATIVO TOTAL & DEPÓSITOS A VISTA & Média PLB \\
\hline \multirow[t]{9}{*}{ Privado Nacional } & ITAU & 750.525 .684 & 26.408 .537 & 0,107 \\
\hline & BRADESCO & 599.228 .137 & 31.955 .652 & 0,154 \\
\hline & VOTORANTIM & 115.568 .061 & 366.174 & 0,007 \\
\hline & SAFRA & 77.199 .212 & 906.151 & 0,028 \\
\hline & $\mathrm{BIC}$ & 17.142 .246 & 501.481 & 0,042 \\
\hline & BANSICREDI & 13.898 .690 & 41.903 & 0,008 \\
\hline & PANAMERICANO & 13.439 .311 & 38.147 & 0,011 \\
\hline & BMG & 11.687 .686 & 92.555 & 0,011 \\
\hline & ALFA & 11.355 .338 & 34.707 & 0,006 \\
\hline \multicolumn{2}{|l|}{ Privado Nacional Total } & 1.610 .044 .365 & 60.345 .307 & 0,105 \\
\hline \multirow[t]{3}{*}{ Público Federal } & BB & 831.673 .963 & 59.077 .080 & 0,173 \\
\hline & CEF & 432.165 .196 & 19.985 .788 & 0,105 \\
\hline & BNB & 24.708 .141 & 124.548 & 0,011 \\
\hline \multicolumn{2}{|l|}{ Público Federal Total } & 1.288 .547 .300 & 79.187 .416 & 0,146 \\
\hline \multirow[t]{7}{*}{ Privado Controle Estrangeiro } & SANTANDER & 391.388 .905 & 14.844 .497 & 0,100 \\
\hline & HSBC & 137.796 .360 & 8.286 .150 & 0,193 \\
\hline & CITIBANK & 55.461 .045 & 3.609 .465 & 0,328 \\
\hline & CREDIT SUISSE & 26.870 .021 & 52.693 & 0,021 \\
\hline & BNP PARIBAS & 24.608 .835 & 65.942 & 0,011 \\
\hline & JP MORGAN CHASE & 16.413 .045 & 56.641 & 0,400 \\
\hline & SOCIETE GENERALE & 13.370 .157 & 4.580 & 0,002 \\
\hline \multicolumn{2}{|c|}{ Privado Controle Estrangeiro Total } & 665.908 .368 & 26.919 .968 & 0,126 \\
\hline Público Estadual & BANRISUL & 33.167 .251 & 2.781 .590 & 0,160 \\
\hline \multicolumn{2}{|l|}{ Público Estadual Total } & 33.167 .251 & 2.781 .590 & 0,160 \\
\hline \multicolumn{2}{|l|}{ Total geral } & 3.597 .667 .284 & 169.234 .281 & 0,125 \\
\hline
\end{tabular}

Fonte: Elaborado pelas autoras a partir de BACEN (2011).

Em termos quantitativos, conforme distribuição apresentada na tabela 2, dentre os 20 maiores bancos em termos de Ativo Total, o Sistema Financeiro Nacional apresenta 45\% de bancos com controle Privado Nacional, 15\% com controle Público Federal, 5\% Público Estadual e 35\% sob controle Privado Estrangeiro. 
Tabela 2 - \% Distribuição por Tipo de Controle

\begin{tabular}{l|c|c}
\hline Tipo de Controle & Qtd de Instituições amostra & \% participação \\
\hline Privado Nacional & 9 & $45 \%$ \\
\hline Público Federal & 3 & $15 \%$ \\
\hline Privado Controle Estrangeiro & 7 & $35 \%$ \\
\hline Público Estadual & 1 & $5 \%$ \\
\hline Total de Instituições da amostra & 20 & $100 \%$ \\
\hline
\end{tabular}

Fonte: Elaborado pelas autoras a partir de BACEN (2011).

Destaca-se que, durante o período analisado, março de 2000 a março de 2011, ocorreram muitas alterações em relação à estrutura de capital e participação de bancos, com extinções e fechamento de bancos, bem como compras e incorporações de instituições. A tabela 3 apresenta a evolução quantitativa geral dos bancos pela estrutura de capital e tipo de controle. Observa-se que, anualmente, entre 2000 e 2011, ocorreu uma redução média de $2 \%$ da quantidade de bancos em operação. No final de 2010, o Sistema Nacional Financeiro apresentou uma redução de 18\% da quantidade de instituições financeiras, quando comparado com a quantidade de bancos em operação no ano de 2000 .

Tabela 3 - Quantitativo de bancos pela estrutura de capital / tipo de controle - 2000 - 2010

\begin{tabular}{l|c|c|c|c|c|c|c|c|c|c|c}
\hline & $\mathbf{2 0 0 0}$ & $\mathbf{2 0 0 1}$ & $\mathbf{2 0 0 2}$ & $\mathbf{2 0 0 3}$ & $\mathbf{2 0 0 4}$ & $\mathbf{2 0 0 5}$ & $\mathbf{2 0 0 6}$ & $\mathbf{2 0 0 7}$ & $\mathbf{2 0 0 8}$ & $\mathbf{2 0 0 9}$ & $\mathbf{2 0 1 0}$ \\
\hline \multicolumn{1}{c|}{ Bancos } & $\mathbf{D e z}$ & $\mathbf{D e z}$ & $\mathbf{D e z}$ & $\mathbf{D e z}$ & $\mathbf{D e z}$ & $\mathbf{D e z}$ & $\mathbf{D e z}$ & $\mathbf{D e z}$ & Dez & Dez & Dez \\
\hline Públicos (2) & 17 & 15 & 15 & 15 & 14 & 14 & 13 & 13 & 12 & 10 & 9 \\
\hline Privados & 175 & 167 & 152 & 150 & 150 & 147 & 146 & 143 & 147 & 148 & 148 \\
\hline Nacionais & 105 & 95 & 87 & 88 & 82 & 82 & 81 & 77 & 78 & 88 & 88 \\
\hline $\begin{array}{l}\text { Nacionais com Participação } \\
\text { estrangeira (3) }\end{array}$ & & & & 10 & 8 & 9 & 10 & 7 & 0 & 0 \\
\hline Controle estrangeiro (4) & & & & & 49 & 49 & 48 & 49 & 56 & 54 & 54 \\
\hline Estrangeiros (5) & 70 & 72 & 65 & 62 & 9 & 8 & 8 & 7 & 6 & 8 & 8 \\
\hline Total & 192 & 182 & 167 & 165 & 164 & 161 & 159 & 156 & 159 & 158 & 157 \\
\hline \% em relação ao ano anterior & & $-5 \%$ & $-8 \%$ & $-1 \%$ & $-1 \%$ & $-2 \%$ & $-1 \%$ & $-2 \%$ & $2 \%$ & $-1 \%$ & $-1 \%$ \\
\hline \multicolumn{1}{c}{$\%$ em relação ao ano 2000 } & & $-5 \%$ & $-13 \%$ & $-14 \%$ & $-15 \%$ & $-16 \%$ & $-17 \%$ & $-19 \%$ & $-17 \%$ & $-18 \%$ & $-18 \%$ \\
\hline
\end{tabular}

Fonte: Cosif - transação PCOS200 (doc. 4016) - Relatório Anual 2010 BACEN. Adaptado pelas autoras.

1- Inclui bancos múltiplos, bancos comerciais e caixa econômica

2- Incluem caixas econômicas (estaduais, em funcionamento até Jan-99, e a Caixa Econômica Federal)

3- Incluem bancos que detém participação estrangeira relevante (conforme Carta-Circular 2.345-93)

4- Bancos múltiplos e comerciais com controle estrangeiro (exceto filiais)

5- Filiais de bancos estrangeiros

* 2000 a 2003 bancos nacionais com participação estrangeira estão sendo considerados na mesma base de bancos nacionais

O gráfico 5 apresenta a evolução, com base nos balanços de todas as instituições financeiras ${ }^{7}$, dos ativos totais, depósitos à vista e operações de crédito do Sistema Financeiro Brasileiro no período de 2000 a 2011. É possível observar, que neste período, o total de depósitos à vista cresceu menos que proporcionalmente às outras duas contas: ativo total e operações de crédito. Nota-se que a partir de 2005 as operações de crédito tiveram um crescimento, assim como o ativo total, enquanto que os depósitos à vista cresceram relativamente menos.

\footnotetext{
Foram consideradas para elaboração deste gráfico todas as instituições financeiras em cada período, conforme demonstrativo da tabela 3 , possibilitando uma análise geral da situação de distribuição dos Ativos e Passivos patrimoniais.
} 
(conclusão)

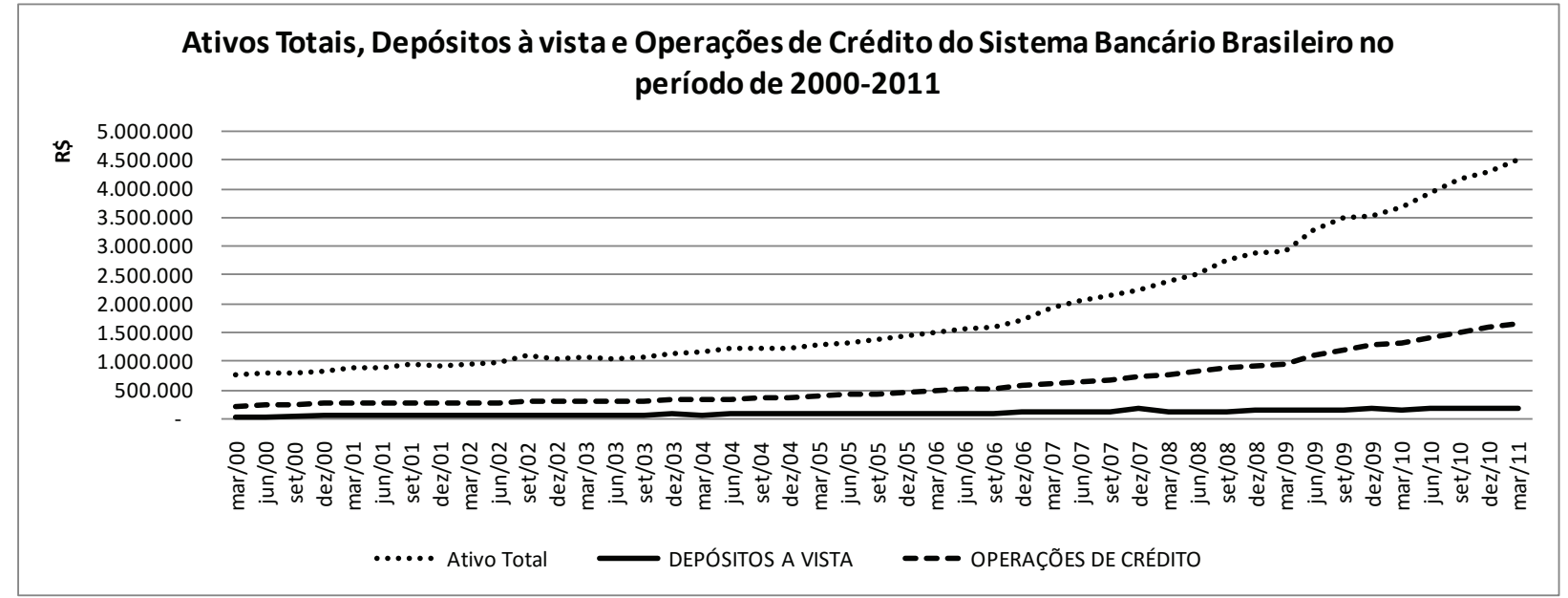

Gráfico 5 - Ativos Totais, Depósitos à vista e Operações de crédito do Sistema Bancário Brasileiro no período de 2000-2011 Fonte: Elaborado pelos autores a partir de BACEN (2011).

A partir da observação do gráfico 5, uma questão importante é identificar as razões das variações observadas no comportamento das contas agregadas dos bancos brasileiros. A tabela 4 apresenta a distribuição percentual das contas patrimoniais do ativo em relação ao ativo total.

As contas que justificam as variações do ativo total são: 1) Aplicações Interfinanceiras ${ }^{8}$, que nos anos de 2009 e 2010 passaram a representar cerca de 20\% do ativo total; 2) Relações interfinanceiras'; 3) Imobilizado de arrendamento ${ }^{10}$; 4) As operações de crédito sobre o ativo total, que correspondiam a $28 \%$ em 2001 e passaram a representar $36 \%$ em 2010.

Por outro lado, a participação da conta TVM e Instrumentos Derivativos ${ }^{11}$ apresentou uma tendência de queda, que se intensificou a partir de 2007, indicando que pode ter ocorrido uma tendência de mudança na atuação os bancos, que aumentaram as operações de crédito, reduzindo as aplicações as aplicações em instrumentos e derivativos, o que significou redução da sua preferência pela liquidez.

Tabela 4 - Distribuição \% das contas patrimoniais em relação ao Ativo Total no período de 2000 - 2011.

(Continua)

\begin{tabular}{|c|c|c|c|c|c|c|c|c|c|c|c|c|}
\hline$\%$ s/ ATIVO TOTAL & $\mathrm{dez} / 00$ & $\mathrm{dez} / 01$ & $\mathrm{dez} / 02$ & $\mathrm{dez} / 03$ & $\mathrm{dez} / 04$ & $\mathrm{dez} / 05$ & $\mathrm{dez} / 06$ & $\mathrm{dez} / 07$ & $\mathrm{dez} / 08$ & $\mathrm{dez} / 09$ & $\mathrm{dez} / 10$ & $\operatorname{mar} / 11$ \\
\hline ATIVO TOTAL & $100 \%$ & $100 \%$ & $100 \%$ & $100 \%$ & $100 \%$ & $100 \%$ & $100 \%$ & $100 \%$ & $100 \%$ & $100 \%$ & $100 \%$ & $100 \%$ \\
\hline Disponibilidades & $1 \%$ & $2 \%$ & $3 \%$ & $2 \%$ & $3 \%$ & $2 \%$ & $1 \%$ & $1 \%$ & $1 \%$ & $2 \%$ & $1 \%$ & $1 \%$ \\
\hline $\begin{array}{l}\text { Aplicações Interfinan- } \\
\text { ceiras }\end{array}$ & $7 \%$ & $9 \%$ & $11 \%$ & $15 \%$ & $11 \%$ & $13 \%$ & $13 \%$ & $15 \%$ & $15 \%$ & $17 \%$ & $20 \%$ & $11 \%$ \\
\hline $\begin{array}{l}\text { TVM e Instrumentos } \\
\text { Financeiros Deriva- } \\
\text { tivos }\end{array}$ & $24 \%$ & $33 \%$ & $31 \%$ & $31 \%$ & $30 \%$ & $28 \%$ & $26 \%$ & $23 \%$ & $23 \%$ & $19 \%$ & $18 \%$ & $19 \%$ \\
\hline $\begin{array}{l}\text { Relações Interfinan- } \\
\text { ceiras }\end{array}$ & $10 \%$ & $9 \%$ & $12 \%$ & $11 \%$ & $11 \%$ & $11 \%$ & $10 \%$ & $9 \%$ & $9 \%$ & $4 \%$ & $4 \%$ & $12 \%$ \\
\hline
\end{tabular}

\footnotetext{
8 Aplicações Interfinanceiras de Liquidez: Compreendem as aplicações feitas em outros bancos via CDI, podendo ser pré ou pós-fixadas. Neste grupo estão as operações com títulos como Debêntures, LFTs (Letras Financeiras do Tesouro), LTNs (Letras do Tesouro Nacional), NTNs (Notas do Tesouro Nacional), LBCs (Letras do Banco Central), etc.

9 Relações interfinanceiras: inclui os cheques e outros papéis entre bancos.

${ }^{10}$ Imobilizado de arrendamento: reúne os bens que foram arrendados, ou seja, que foram envolvidos em operação de leasing.

${ }^{11}$ Instrumentos Financeiros Derivativos: são os que derivam ou dependem do valor de outro ativo e que se caracterizam, normalmente, como contratos padronizados, negociados entre as partes em mercados secundários organizados ou contratos ad hoc entre os agentes.
} 


\begin{tabular}{|c|c|c|c|c|c|c|c|c|c|c|c|c|}
\hline $\begin{array}{l}\text { Relações Interdepen- } \\
\text { dências }\end{array}$ & $0 \%$ & $0 \%$ & $0 \%$ & $0 \%$ & $0 \%$ & $0 \%$ & $0 \%$ & $0 \%$ & $0 \%$ & $0 \%$ & $0 \%$ & $0 \%$ \\
\hline $\begin{array}{l}\text { Oper. Créd. e Arrend. } \\
\text { Mercantil Total }\end{array}$ & $35 \%$ & $29 \%$ & $28 \%$ & $28 \%$ & $30 \%$ & $32 \%$ & $34 \%$ & $33 \%$ & $33 \%$ & $33 \%$ & $36 \%$ & $38 \%$ \\
\hline Provisão p/CL & $-3 \%$ & $-3 \%$ & $-2 \%$ & $-2 \%$ & $-2 \%$ & $-2 \%$ & $-3 \%$ & $-2 \%$ & $-2 \%$ & $-2 \%$ & $-3 \%$ & $-2 \%$ \\
\hline Outros Créditos & $18 \%$ & $15 \%$ & $13 \%$ & $11 \%$ & $12 \%$ & $11 \%$ & $12 \%$ & $13 \%$ & $13 \%$ & $17 \%$ & $13 \%$ & $13 \%$ \\
\hline Outros Valores e Bens & $1 \%$ & $0 \%$ & $0 \%$ & $0 \%$ & $0 \%$ & $1 \%$ & $1 \%$ & $1 \%$ & $1 \%$ & $1 \%$ & $0 \%$ & $0 \%$ \\
\hline $\begin{array}{l}\text { Imobilizado de Arren- } \\
\text { damento }\end{array}$ & $2 \%$ & $1 \%$ & $1 \%$ & $1 \%$ & $1 \%$ & $2 \%$ & $3 \%$ & $4 \%$ & $4 \%$ & $6 \%$ & $6 \%$ & $4 \%$ \\
\hline Permanente (*) & $4 \%$ & $4 \%$ & $3 \%$ & $3 \%$ & $3 \%$ & $3 \%$ & $3 \%$ & $3 \%$ & $3 \%$ & $4 \%$ & $4 \%$ & $4 \%$ \\
\hline
\end{tabular}

A partir desta exposição, apresenta-se a análise do índice de PLB, que mostra a relação de depósitos à vista sobre operações de Crédito. A ideia principal é analisar, através deste índice, como o sistema bancário alocou, no período estudado, os seus recursos entre ativos de maior ou menor liquidez levando em conta o tipo de controle bancário (público, privado, nacional ou estrangeiro).

Assim, tem-se que os depósitos à vista correspondem à intenção do público de manter seus ativos mais líquidos possíveis enquanto as operações de crédito correspondem a disposição dos bancos em concederem empréstimos, tornando seus ativos mais ou menos líquidos. Espera-se que quanto maior for o índice, maior é a preferência pela liquidez dos bancos, nesta situação deve-se avaliar se são os bancos que emprestam mais (ou menos), ou se é o público está aumentando (ou reduzindo) as suas aplicações em depósitos à vista, e buscando alternativas de menor grau de liquidez, como poupança e depósitos a prazo.

Nos gráficos 6, 7, 8 e 9 é apresentada a evolução do PLB médio dos bancos, conforme o tipo de controle: público federal, privado nacional, privado com controle estrangeiro e público estadual. A partir desta exposição é possível identificar algumas tendências em relação ao PLB.

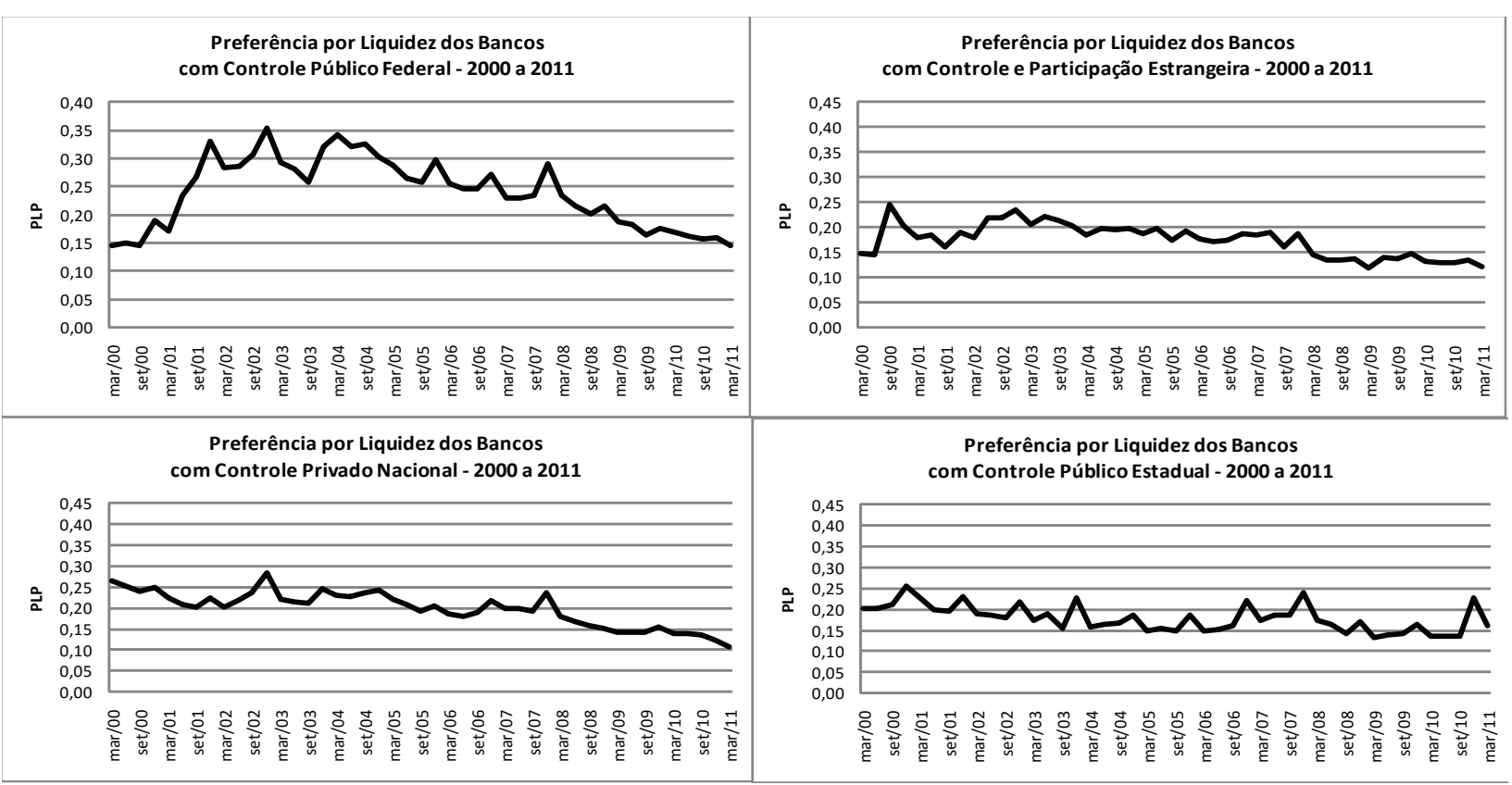

Gráficos 6, 7, 8 e 9. Preferência por Liquidez dos Bancos - PLB Tipo de Controle período de 2000 a 2011 Fonte: Elaborado pelas autoras a partir de BACEN (2011).

Observa-se, com base nos gráficos 6, 7, 8 e 9, que em praticamente todo o período analisado a preferência por 
liquidez é mais elevada nos bancos de controle público federal. Além disso, a PLB apresenta picos que compreendem os anos 2000-2003, provavelmente em virtude da conjuntura interna e externa desfavorável, marcada por diversas crises em vários países do mundo.

A partir de 2004, nota-se uma tendência à redução do índice de PLB, que se cai ainda mais a partir do ano de 2008. A preferência pela liquidez dos bancos Públicos Federais foi em, em 2010, de 14,6\%. Estima-se, no entanto, que ocorreu um maior aumento na concessão de empréstimos, pelos bancos CEF, cujo índice no mesmo ano representou 11,66\%. O BNB - Banco do Nordeste do Brasil, também apresentou um índice PLB bastante baixo, a média, em 2010, foi de $1,2 \%$, quando o total de operações de crédito teve um crescimento de 19,3\% contra um crescimento de $9 \%$ na conta de Depósitos à vista. Dentre os bancos públicos federais o Banco do Brasil é o que apresenta maior índice de PLB, em média, 18,5\%, em 2010, não obstante esse índice tenha se reduzido em relação aos anos anteriores, quando chegou a alcançar 35,4\%. Para esse banco, se comparado ao mês 03/2008, em 03/2010, houve um crescimento de 40\% dos depósitos à vista contra um crescimento de $114 \%$ das operações de crédito, justificando assim a redução do índice.

Já os bancos de controle privado nacional, apresentaram PLB mais baixo, principalmente a partir de 2007, devido ao aumento no nível de operações de crédito a desde então. Os maiores bancos privados nacionais, no ano de 2010, apresentaram um PLB médio de 12,9\%. Entretanto, é importante destacar que os bancos Itaú e Bradesco são os que apresentaram o índice de PLB em 2010, respectivamente, 19\% e 21,4\%. Os demais bancos: Alfa, BANCOOB, BIC, BMG, Fibra, Panamericano ${ }^{12}$ e Votorantim apresentaram, por sua vez, um índice de PLB de 1,8\%. Este baixo índice é justificado pela natureza e foco das operações destes bancos, que atuam especialmente na concessão de crédito para pessoas jurídicas.

Em relação à evolução do índice PLB dos bancos privados com controle estrangeiro, destaca-se que há uma tendência de queda no indicador, justificada pelo aumento de concessão de empréstimos no período. Comparando-se o período de 03/2008 e 03/2011, identifica-se um crescimento de 103\% dos depósitos à vista, contra um crescimento de 141\% das operações de concessão de crédito, justificando assim a redução do índice.

O índice de PLB do banco público estadual, que é representado pelo Banco do Rio Grande do Sul - Banrisul apresentou uma tendência diferenciada em relação ao que foi apresentado pelos bancos privados e públicos federais, cujo PLB, ano de 2010, foi de 16,0\%. No referido banco, houve um crescimento de $158 \%$ dos depósitos à vista contra 95\% das operações de crédito, implicando no aumento do índice se deu principalmente pelo aumento da preferência por liquidez por parte do público ou pela redução na concessão de empréstimos.

O gráfico 10 sintetiza a evolução do indicador considerando todos os tipos de controle acionário. A partir deste comparativo, é possível identificar que a trajetória do PLB é similar para todos os tipos de banco, ainda que em proporções diferenciadas conforme o controle bancário. Especialmente nos anos iniciais da série houveram maiores picos e quedas do PLB. Já a partir de 2007, houve uma tendência geral em relação de queda da preferência pela liquidez das diferentes instituições financeiras.

\footnotetext{
12 Em função dos escândalos contábeis do banco Panamericano identificou-se que houve um aumento de 81,2\% no índice PLB entre a média (jun/2009 a dez/2010) e mar/2011 (passou de 0,6\% para 1,1\%). O volume de Operações de Crédito foi reduzido em $40 \%$ no último ano.
} 


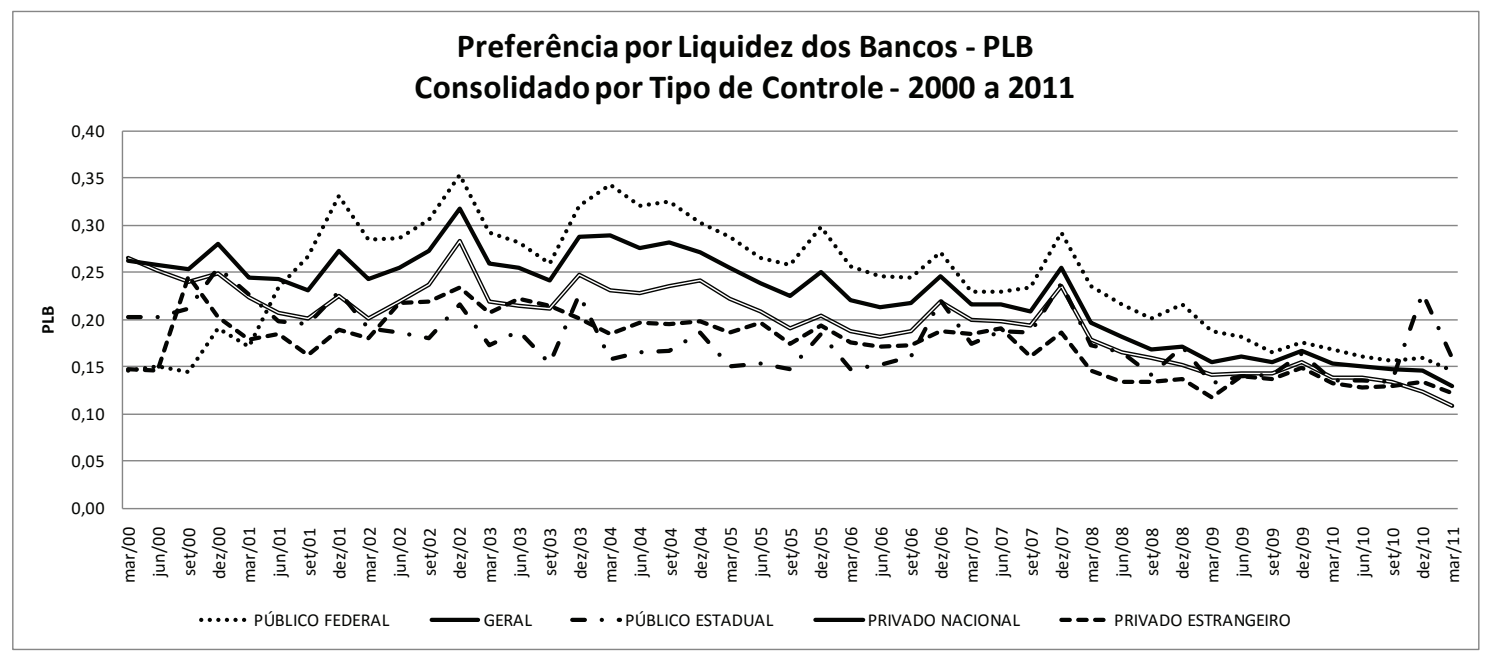

Gráfico 10. Preferência por Liquidez dos Bancos - PLB Consolidado por Tipo de Controle - 2000 a 2011 Fonte: Elaborado pelas autoras a partir de BACEN (2011).

Finalmente, uma análise relevante é feita a partir da comparação do PLB dos bancos de maior porte com os de menor porte. Para isto selecionou-se os cinco bancos ${ }^{13}$ que apresentaram em 03/2011 menor Ativo Total e que operavam com saldo na conta Depósitos à Vista, confrontando com o índice de PLB dos cinco maiores bancos ${ }^{14}$.

O gráfico 11 mostra que o índice de PLB dos bancos de menor porte é mais baixo que dos bancos de maior porte. Em média, os cinco maiores bancos possuíam, no ano de 2000, o PLB de 19,4\%, o qual passou a ser, em 2010 de 14,9\% em média. Os cinco menores bancos, por sua vez, tinham, em 2000, um índice de PLB de 11,1\%, o qual se reduziu, em 2010, para 5,2\%.

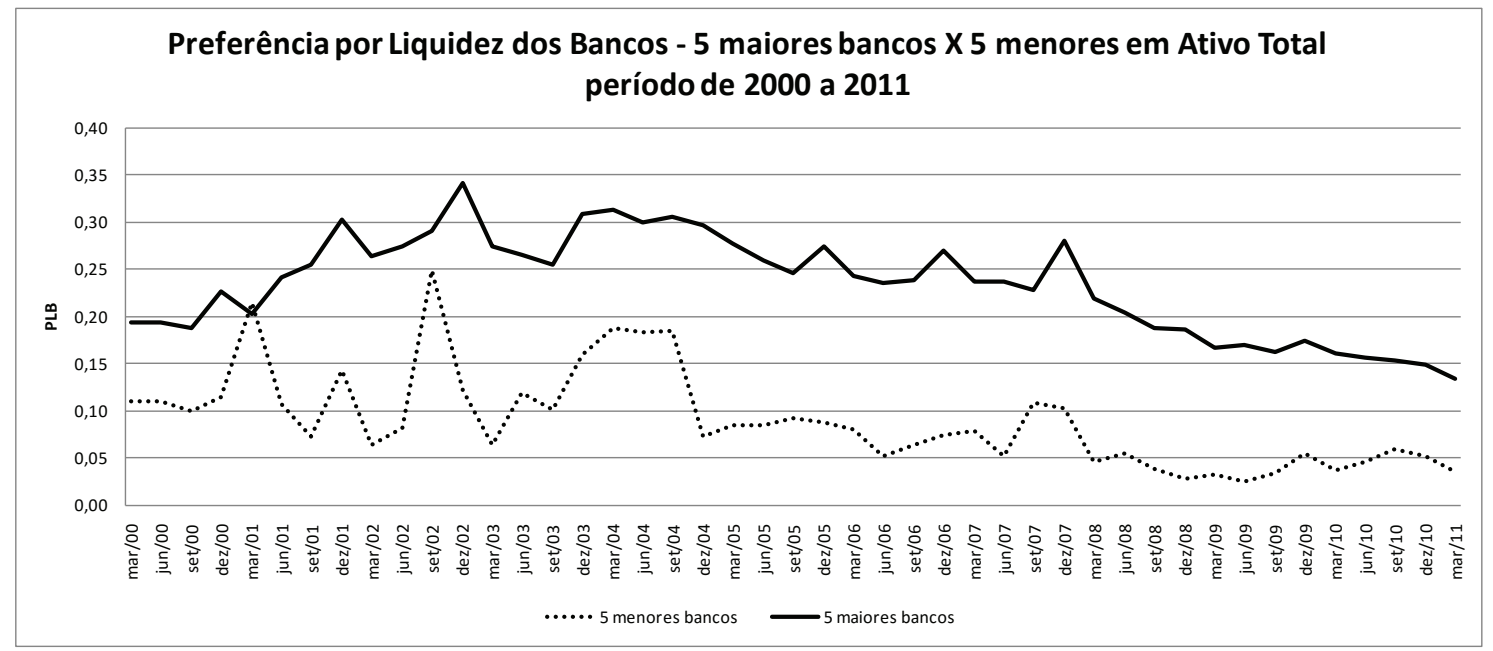

Gráfico 11. Preferência por Liquidez dos Bancos - Comparativo entre os 5 maiores bancos e 5 menores bancos em termos de Ativo Total no período de 2000 a 2011

Fonte: Elaborado pelas autoras a partir de BACEN (2011).

Uma observação possível é que, esse comportamento é motivado pelo fato de que os bancos de menor porte possuem um volume significativamente menor de depósitos à vista, quando comparados com as instituições de maior porte, o que se reflete em um menor índice de preferência pela liquidez, nestas organizações.

\footnotetext{
13 Bancos selecionados com menor Ativo Total em março/2011: Arbi, Azteca, Bancap, Credibel e La Republica.

14 Bancos selecionados com maior Ativo Total em março/2011: BB, Bradesco, CEF, Itaú e Santander.
} 


\section{CONSIDERAÇÕES FINAIS}

Este artigo analisou o comportamento do Sistema Financeiro Brasileiro, com foco no setor bancário e seu grau de preferência pela liquidez, no período compreendido entre os anos de 2000 e 2011.

A preferência pela liquidez é um conceito de grande importância, tendo sido discutido por Keynes [1976(1936)], segundo o qual, em se referindo às economias monetárias de produção, a principal característica é a incerteza. A incerteza ao afetar o estado de confiança dos agentes, torna precária a base de conhecimento para cálculos da renda esperada e reduz o grau de confiança quanto ao futuro. Essa atitude irá levar a que estes prefiram alocar seus recursos em ativos líquidos, pelo que a moeda surge como o ativo líquido por excelência.

Essa atitude de preferência pela liquidez se reflete sobre o desenvolvimento econômico, uma vez que os agentes postergam suas decisões de consumo e investimento, impactando negativamente sobre a demanda agregada. O que dizer então quando os próprios agentes do sistema financeiro são os que possuem grau considerável de preferência pela liquidez?

Nessa perspectiva, o escopo deste trabalho, buscou evidências desse comportamento para o sistema bancário brasileiro, a partir dos dados dos balanços contábeis dos 20 maiores bancos brasileiros, que perfazem $95 \%$ do ativo total dos bancos. O índice PLB representa entre o total de depósitos à vista e as operações de crédito das carteiras dos bancos. Os depósitos à vista correspondem à intenção do público de manter maior grau de liquidez e, as operações de crédito, a disposição dos bancos em conceder empréstimos abrindo mão de liquidez. Quanto maior o índice, maior a preferência pela liquidez por parte dos bancos.

Os principais resultados a que chegou o presente estudo sugeriram uma trajetória de redução geral do índice de preferência pela liquidez, o que ocorreu em função da expansão substancial das operações de crédito no Brasil, em todos os ramos de atividade, notadamente após 2007. Vale destacar, que o índice continua elevado e é mais alto para os bancos de controle público federal e público estadual e mais baixo para os bancos com controle privado nacional e controle privado estrangeiro.

A preferência pela liquidez média dos bancos públicos federais foi, em 2010, de 14,6\%, sendo mais reduzida para alguns deles como a CEF, cujo índice de PLB foi de 11,66\% e também o BNB que apresentou um índice de PLB bastante baixo, 1,2\% no mesmo ano. Dentre os bancos públicos federais o Banco do Brasil é o que apresenta maior índice de PLB, a média em 2010 foi de 18,5\%, ainda que tenha se reduzido em relação ao inicio do período analisado, quando chegou a alcançar 35,4\%.Já os bancos de controle privado nacional apresentaram um índice de PLB sensivelmente mais baixo ficando, em média, em 12,9\% no ano de 2010. Entretanto, é importante destacar que os bancos Itaú e Bradesco foram os que apresentam maior índice de PLB registrando, respectivamente, 19\% e 21,4\%, no mesmo ano. Os demais bancos: Alfa, BANCOOB, BIC, BMG, Fibra, Panamericano ${ }^{15}$ e Votorantim apresentaram em média no mesmo período um índice PLB de apenas 1,8\%.

Em relação à evolução do índice PLB dos bancos privados com controle estrangeiro, destaca-se que há tendência de queda no indicador, justificada pelo aumento de concessão de empréstimos no período. O índice de PLB do banco público estadual, que é representado pelo Banco do Rio Grande do Sul - Banrisul apresentou uma tendência diferenciada em relação ao que foi apresentado nos bancos privados e públicos federais. O PLB no ano de 2010 foi de 16,0\%, mas os depósitos à vista tiveram crescimento superior ao crescimento das operações de crédito, ao longo do período.

Com relação ao tamanho, os maiores bancos foram os que apresentaram os maiores índices de preferência pela liquidez. Em média, os cinco maiores bancos possuíam, no ano de 2000, o PLB de 19,4\%, o qual passou a 14,9\%, em média, no ano de 2010. Os cinco menores bancos, por sua vez, tinham, em 2000, um índice de PLB de 11,1\%, que se reduziu, em 2010 , para $5,2 \%$.

\footnotetext{
15 Em função dos escândalos contábeis do banco Panamericano identificou-se que houve um aumento de 81,2\% no índice PLB entre a média (jun/2009 a dez/2010) e mar/2011 (passou de 0,6\% para 1,1\%). O volume de Operações de Crédito foi reduzido em 40\% no último ano.
} 
Os resultados sugeriram que o comportamento do setor bancário embora tenha um alto índice de PLB, vem reduzindo esta preferência. Por um lado, observou-se uma redução relativa das operações com títulos e derivativos, paralelamente ao aumento das operações de concessão de crédito. A remuneração dos títulos públicos à taxa SELIC, substancialmente elevadas, são à visão dos bancos brasileiros, opções bastante lucrativas e líquidas, mas que ainda são superadas pelos ganhos das operações de créditos às pessoas físicas e jurídicas, cujas taxas de juros de mercado alcançaram 40,7\% e 26,5\% respectivamente, em média no ano 2010, bem como o spread cobrado nas operações de crédito à pessoa física, foi de $27,7 \%$.

Os resultados do presente trabalho sugerem, ante a importância do setor financeiro e o papel do crédito para o desenvolvimento, que a atuação do setor bancário tem dado uma menor contribuição ao desenvolvimento do que poderia efetivamente propiciar, tendo em vista a preferência pela liquidez desses agentes, bem como a conjuntura brasileira em que a relação entre rentabilidade e risco não é tão conflituosa como normalmente se sugere.

ABSTRACT: This article analyzes the Brazilian Financial System focusing on the banking sector and its degree of liquidity preference that means the interest of agents to preserve their portfolios in higher liquidity assets instead of the less liquid, as discussed by Keynes [1976(1936)]. To this proposal we have calculated the Liquidity Preference index (PLB) for the 20 largest banks in period 2000-2011 which represent $95 \%$ of the total asset banking and then evaluated the behavior of this index PLB according to the type of control: public federal, state, public, private domestic and private foreign controlled and even regarding to the size of the banks. The main results suggested a trend of overall reduction in liquidity preference due to the increase of credit operations after 2007, however, it was noted that although high, the PLB index is lower for private banks and higher for both federal and state public banks. Regarding the size, we noted that the larger bank has presented the highest levels of PLB. These results are apparently contradictory both, theoretically and even related to economic policies adopted since the mid-2000s, suggesting the importance of a deeper discussion about the causes and especially the consequences this kind of behavior for the economic development in the country.

Key-words: Financial System; Liquity Preference; Banking Sector; Brazilian Economy.

\section{REFERÊNCIAS}

Banco Central do Brasil - BACEN. Informações contábeis das instituições financeiras. Disponível em: <www. bcb.gov.br > . Acesso em 11/06/11.

. Boletim do Banco Central. Disponível em: <www.bcb.gov.br>. Acesso em 08 fev. 2014.

CARVALHO, F. Economia monetária e financeira. Ed. Campus: Rio de Janeiro, 2007.

CAVALCANTE, A.; CROCCO, M.; JAYME JÚNIOR, F. Preferência pela liquidez, sistema bancário e disponibilidade de crédito regional. Texto para discussão; 237. UFMG - Cedeplar: Belo Horizonte, 2004.

DAVIDSON, P. Post keynesian macroeconomic theory. Edward Elgar Publishing: Aldershot, 1994.

FERRARI FILHO, F. As propostas keynesianas de reforma do sistema monetário internacional: em busca da neutralidade da moeda de conversibilidade internacional? Revista de Economia, v.32, n.2, UFPR, 2006. p. 7-20

HERMANN, J.; PAULA, L. Economic development and the functionality of the financial system in brazil: a post keynesian approach. Associação Keynesiana Brasileira, 2011. 
JAIME JR., F.; ROMERO, J. Crédito, preferência pela liquidez e desenvolvimento regional: o papel dos bancos públicos e privados no sistema financeiro brasileiro (2001 - 2006). XIV Encontro Nacional de Economia Política. Uberlândia, 2009.

PAULA, L. Dinâmica da firma bancária: uma abordagem não convencional. Revista Brasileira de Economia, Rio de Janeiro, v. 53, n. 3, 1999. p. 323-356.

KEYNES, J. Treatise on Money. New York: MAS Press, 1976.

. A teoria geral do emprego, do juro e da moeda. São Paulo: Abril Cultural, 1983.

SANT'ANNA, A.; BORÇA JUNIOR, G.; ARAÚJO, P. Mercado de crédito no Brasil: evolução recente e o papel do BNDES (2004-2008). Revista do BNDES, v. 16, n. 31, Rio de Janeiro, 2009. p. 41-60

TADA, G. Crédito bancário e desenvolvimento regional no período 2004-2009: o enfoque pós Keynesiano da não neutralidade da moeda. Monografia à Universidade Federal de Maringá, 2010. 